\title{
THE INFLUENCE OF PASSENGER DEMOGRAPHICS ON AIRPORT ATTRIBUTE EVALUATION
}

\author{
STEPHEN CARSTENS* \\ GERT HEYNS** \\ *stephcar@global.co.za \\ Institute of Transport and Logistics Studies (Africa) \\ University of Johannesburg \\ South Africa \\ **gjheyns@uj.ac.za \\ Institute of Transport and Logistics Studies (Africa) \\ University of Johannesburg \\ South Africa
}

\begin{abstract}
It is imperative for airport operators and airlines to have a clear understanding of the factors which influence the passenger's decision with regard to which airport/airline combination to use in a multi-airport scenario. Interactions between demographic variables, such as gender and purpose of travel, and the choice attributes in the decision-making process exist. The extent to which specific attributes influence the passenger's decision could be invaluable to service providers (airport operators and airlines) in allocating and employing limited resources. The purpose of this article is to investigate the extent of the interactions between passenger demographics and attribute evaluation by taking into account the ordinal nature of the measurement scale.
\end{abstract}

\section{INTRODUCTION}

Air transport is becoming increasingly more popular in South Africa. This is illustrated by an increase of approximately $66 \%$ in the number of domestic passengers over the period 2002 to 2010 at the airports managed by the Airports Company South Africa (ACSA) (Airports Company South Africa, 2011). ACSA, which is majority owned by the South African Government, manages nine airports in South Africa including all the international airports (Airports Company South Africa, 2011). The increase in air passenger transport was mainly the result of the introduction of a low cost carrier (LCC) in the South African market in 2001 (Comair, 2011). Initially the LCCs operated from the ACSA-operated airports but they also started operating from a regional airport, Lanseria International Airport (LIA) in Johannesburg, Gauteng, in 2006, which is privately owned (Heyns \& Carstens, 2011). A second LCC started operating at LIA in 2011 (Heyns et al., 2011). The two airports in Johannesburg that the LCCs currently utilise are OR Tambo International Airport (ORTIA) 
situated in the east of the city and Lanseria International Airport (LIA) situated west of Johannesburg and which is approximately $55 \mathrm{~km}$ from ORTIA.

Airlines and airport operators are under significant financial pressures and are continually pursuing avenues to optimise the utilisation of limited resources. Therefore, an understanding of the passenger's view of the factors which influence their decision as to which airport/airline combination to use in a multi-airport scenario is beneficial to both the airport operators and the relevant airlines. The airport operators have control over certain attributes such as the number of parking bays, the number of check-in points, etc. Attributes which are mainly related to the geographic location of the airport, e.g. the time to access the airport, fall outside the control of the operator but may still have a significant influence on the passenger's airport decision. Similarly, airlines have control over a number of their service attributes such as frequency of services, the fare, etc.

The service providers (airport operators and airlines) need to understand the relationship between their service levels and a passenger's airport and airline decision as passenger migrations between airports impact on the airport operation's capacities (Heyns et al., 2011). Airlines and airport operators globally face the same challenges to understand which factors influence the decision-making process of passengers in airport choice (Pels, Nijkamp \& Rietveld, 2003; Marcucci \& Gatta, 2011).

Individuals make decisions by comparing alternatives and selecting an action (Hensher, Rose \& Green, 2006). These decisions are subject to a large amount of variability (heterogeneity) and in order to model decision-making this variability needs to be explained. This is based on the fact that it is an individual's level of preference for a specific alternative that determines which choice will be selected (Hensher et al., 2006). There are various ways of measuring the level of preference, one of which is an ordinal measurement, i.e. a ranking score. An ordinal measurement will provide an indication if one level of an attribute is more preferred than another.

Heyns et al. (2011) completed a survey at LIA to determine the factors that have the most significant influence on a passenger's decision as to which airport to use. Most of the research done on air passenger choice behaviour treats all individuals in the same fashion. However, Hess, Adler and Polak (2007) have found significant interactions between socio-demographic variables, particularly the purpose of travel and the sensitivity to travel attributes. Hess et al. (2007) based their findings on the results of a discrete choice model and the subsequent willingness-to-pay measures. This interaction between the demography of the sample and attribute selection was also found by Heyns et al. (2011) as indicated by the changes in the underlying decision factors based on gender and purpose of travel. However, Heyns et al. (2011) did not establish the extent (level of preference) to which a 
specific attribute influences the passenger's decision. Such information could be invaluable to service providers in guiding them to utilise limited resources more efficiently and this could be achieved by analysing the ranking scores of the relevant attributes.

The objective of this research is to investigate the extent of the interactions between passenger demographics, with specific reference to gender and the purpose of travel, and attribute evaluation. The research question may be formulated as follows: At what level does gender or purpose of travel impact on the attributes that influence the passenger's airport/airline decision? The proposed method takes into account the ordinal nature of the information, which is then used to estimate response level probabilities.

\section{LITERATURE REVIEW}

Many studies have been completed relating to the airport/airline decision based on discrete choice models. These studies result in models that will predict the choice of an individual given a certain set of alternatives based on the relevant attributes (Hensher et al., 2006). In addition, willingness-to-pay measures may be used to quantify the impact of covariates (respondent demographics) on the choice selection (Hensher et al., 2006). Hess et al. (2007) found significant differences in the evaluation of airport/airline attributes based on the purpose of travel. Marcucci et al. (2011) used a similar approach to analyse consumer behaviour related to regional airport choice and concluded that gender does not have a significant influence on the estimation results. Choice probability elasticities were used by Pels et al. (2003) to identify differences in attributes evaluation based on the purpose of travel.

A quantitative technique that takes the ordinal nature of the response into account is the ordinal regression approach. This method is a form of the generalised linear models and has a wide application provided that the responses (attribute levels) have been ranked in order of preference. Ordinal regression was used by Zhou, Wu, Yang and Jiao (2008) to identify the relationships between consumers and products based on product design. Ananth and Kleinbaum investigated the use of different generalised linear models in the health industry based on a single covariate (Ananth \& Kleinbaum, 1997). These models are developed under relatively strong assumptions and are applicable if the assumptions are satisfied (Ananth et al., 1997). The use of ordinal regression models was further promoted in the health industry by Bender and Benner (2000) who argued that these models should be more widely used in epidemiology and biomedical research.

The ordinal regression model was used by Chen and Hughes (2004) to analyse student satisfaction at higher education institutions. Although gender was included as one of the covariates, it was found not to be significant. Chen et al. (2004) discuss some of the advantages of using the ordinal regression model such as the ease of assessing the validity 
of the assumptions, as well as the little effort involved in estimating and interpreting the model. Akman and Mishra (2010) found through the application of multiple ordinal regression models that gender has no predictive effect on the average daily use of the Internet, i.e. there is no gender difference in terms of the average daily use of the Internet.

A study that used the ordinal regression model to evaluate passenger satisfaction of airport/ airline service levels was completed by Eboli and Mazulla (2009). One of the objectives of this research was to identify critical service aspects available at the airport terminal. Passengers were asked to evaluate (on an ordinal scale) a number of service quality aspects such as availability and frequency of bus links and security against theft (Eboli et al., 2009). The authors state that demographics should be used to identify various market segments, if these exist. In addition, such a model can be used to determine the level combinations of service aspects which contribute to the passenger's overall satisfaction (Eboli et al., 2009).

The use of ordinal regression methods is indeed widespread and Denham (2010) argues that scholars in social research should use quantitative techniques such as ordinal regression to supplement the more general approaches to statistical analysis.

\section{STUDY METHODOLOGY}

This research is based on the results of a paper-based survey of $210^{1}$ randomly selected departing passengers at LIA² (Heyns et al., 2011). The objective of the survey was to establish the most important attributes (factors) that passengers take into account in the selection of the airport (LIA). The survey used a questionnaire which included 18 attributes relating to demographics and the following areas of interest: (1) price, (2) service, (3) convenience, and (4) safety. The demographic information included, inter alia, the gender of the respondent, as well as the purpose of travel, i.e. business, leisure, sport, student and VFR (visiting friends and relatives). Respondents were requested to complete a 4-point Likert-type scale to rank the impact of each attribute on their decision to use LIA as follows: (1) to no extent, (2) to a small extent, (3) to a moderate extent and (4) to a large extent.

The demographic characteristics (gender and purpose of travel) of the respondents who participated in the questionnaire are depicted in Tables I and II.

\footnotetext{
1 Three respondents were removed from the analysis since they were foreigners.

2 Only LCC (no FCC) visit LIA. Survey only includes LCC passengers, which could be seen as a potential weakness of the study.
} 
Table I: Gender

\begin{tabular}{|l|c|c|}
\hline Gender & Frequency & Percent \\
\hline Female & 90 & 43.5 \\
\hline Male & 117 & 56.5 \\
\hline Total & $\mathbf{2 0 7}$ & $\mathbf{1 0 0}$ \\
\hline
\end{tabular}

Table II: Purpose of travel

\begin{tabular}{|l|c|c|}
\hline \multicolumn{1}{|c|}{ Purpose } & Frequency & Percent \\
\hline Business & 107 & 51.7 \\
\hline Leisure & 76 & 36.7 \\
\hline Sport & 2 & 1 \\
\hline Student & 4 & 1.9 \\
\hline VFR & 18 & 8.7 \\
\hline Total & $\mathbf{2 0 7}$ & $\mathbf{1 0 0}$ \\
\hline
\end{tabular}

The majority of the respondents were male (56\%) and the respondents were approximately evenly split in terms of the purpose of travel, i.e. Business (51.7\%) and Other (leisure, sport, student and VFR) (48.3\%).

Heyns et al. (2011) used factor analysis to identify four latent factors that related to the following 12 attributes:

- On-time arrival/departure

- Frequency of service

- Seat availability

- Departure time

- Time to/from the airport

- Ease of access

- Ease of check-in

- Airport safety

- Parking security

- Price of ticket

- Cost of parking

- Cost of transport to the airport

The focus of this research is on these 12 attributes in order to investigate the relationship between the ranking of the attribute and gender of the passenger and his/her purpose of travel. 
This can be achieved by applying a model that takes into account the ordinal nature of the dependent variable (the ranking for each attribute). One such model is the ordinal regression model or generalised linear model for ordinal data (Ananth et al., 1997). The general form of the ordinal regression model is:

$\operatorname{link}\left(\gamma_{j}\right)=\theta_{j}-\left(\beta_{1} x_{1}+\beta_{2} x_{1}+\ldots .+\beta_{k} x_{k}\right)$

where $\gamma j$ is the cumulative probability of the $j$ th category (prob(event $)$ ), $\theta_{j}$ is the threshold for the jth category and $\beta_{1}, \beta_{2}, \beta_{3}, \ldots \beta_{k}$ are the regression coefficients of the independent variable $x_{1}, x_{2}, x_{3}, \ldots x_{k}$. Note that this model is linear in the parameters through the link function. For this research, only one independent variable is used, either gender or purpose of travel. The purpose of travel was categorised in two categories, Business and Other (leisure, sport, student and VFR) to allow sufficient responses per response category. Therefore, both these variables are binary in the sense that each variable has only two levels (options).

The link function is a function of probabilities that results in the linear model. There are various link functions (Norusis, 2011) but the link functions utilised in this research are the following:

- The logit model is based on the logit function (logarithm of the odds ratio) for evenly distributed categories as follows:

$\ln \left[\frac{\operatorname{prob}(\text { event })}{(1-\operatorname{prob}(\text { event }))}\right]=\beta_{0}+\beta_{1} x$

- The complementary log-log model is more suitable for situations where the higher categories are more probable:

$$
\ln (-\ln (1-\operatorname{prob}(\text { event })))=\beta_{0}+\beta_{1} x
$$

- The negative log-log model is more suitable for situations where the lower categories are more probable:

$-\ln (1-\operatorname{prob}($ event $))=\beta_{0}+\beta_{1} x$

The estimated model provides an indication of the affect (estimated coefficient) of the independent variable on the link function. In addition, the inverse of the estimated model allows for the calculation of the cumulative probabilities of selecting the different ratings (Norusis, 2011). By subtracting sequential cumulative probabilities the individual response probabilities can be calculated. These response probabilities indicate the probability 
of each response category being selected, i.e. (1) to no extent, (2) to a small extent, (3) to a moderate extent and (4) to a large extent. The resultant information will indicate how the independent variable (demographic variable) levels impact on the importance of the response category. For example, the calculated response category probabilities will indicate how female passengers rank an attribute and how male passengers rank the attribute. A significant model will be estimated if there is a statistically significant difference in ranking between female and male passengers.

The data was analysed with the PLUM (polytomous universal model) function of SPSS for Windows version 18. This analysis provides the parameter estimates, as well as estimated probabilities for the different response categories: (1) to no extent, (2) to a small extent, (3) to a moderate extent and (4) to a large extent.

The following tests are included in this procedure and were used to determine the significance of the estimated model:

\section{Overall model fit}

The null hypothesis is that the independent variable coefficient is zero. If gender or the purpose of travel has a significant influence on the ranking of the attribute the null hypothesis is rejected (significance $<0.05$ ).

\section{Goodness-of-fit}

Two measures are used, i.e. Pearson and Deviance. The null hypothesis is that the observed and expected frequencies do not differ significantly. If the independent variable has a significant influence on the ranking of the attribute the null hypothesis cannot be rejected (significance $>0.05$ ).

\section{Wald test on the parameter estimates}

This measure tests the significance of the independent variable. The null hypothesis states that the parameter estimate is zero. If the independent variable has a significant influence on the ranking of the attribute the null hypothesis is rejected (significance $<0.05$ ).

\section{Test of parallel lines}

The null hypothesis states that the coefficients are the same across response categories. If the null hypothesis cannot be rejected the ordinal model is applicable (significance $>0.05$ ). This is one of the fundamental assumptions of the ordinal regression model. 


\section{DISCUSSION OF RESULTS}

All three link functions were applied to the data with first, gender (male or female) as the independent variable and secondly, with purpose of travel (business or other) as the independent variable to establish the individual impacts of these variables on the selection of response categories.

\section{Gender}

The results of the model with gender as the independent variable are shown in Tables III to V.

Table III: Logit estimation results

\begin{tabular}{|l|c|c|c|c|c|c|}
\hline \multirow{2}{*}{\multicolumn{1}{c|}{ Logit estimation }} & Coefficient Estimate & \multicolumn{5}{|c|}{ Significance (p-value) } \\
\cline { 2 - 7 } & Gender & Coefficient Estimate & Model fit & Pearson & Deviance & $\begin{array}{c}\text { Test of Parallel } \\
\text { Lines }\end{array}$ \\
\hline On-time arrival/departure & 0.559 & 0.033 & 0.031 & 0.932 & 0.932 & 0.932 \\
\hline Frequency of service & 0.557 & 0.031 & 0.031 & 0.407 & 0.412 & 0.412 \\
\hline Seat availability & 0.644 & 0.013 & 0.013 & 0.459 & 0.456 & 0.465 \\
\hline Departure times & 0.722 & 0.006 & 0.005 & 0.767 & 0.769 & 0.769 \\
\hline Time to/from the airport & 0.758 & 0.027 & 0.024 & 0.458 & 0.459 & 0.459 \\
Ease of access & 0.146 & 0.629 & 0.628 & 0.154 & 0.152 & 0.152 \\
Ease of check-in & 0.553 & 0.061 & 0.059 & 0.995 & 0.995 & 0.995 \\
\hline Airport safety & 0.549 & 0.034 & 0.034 & 0.306 & 0.312 & 0.312 \\
Parking security & 0.294 & 0.257 & 0.26 & 0.138 & 0.133 & 0.133 \\
\hline Price of ticket & 0.941 & 0 & 0 & 0.625 & 0.624 & 0.624 \\
\hline Cost of parking & 0.287 & 0.282 & 0.283 & 0.254 & 0.248 & 0.248 \\
\hline Cost of transport to the airport & 0.441 & 0.088 & 0.088 & 0.633 & 0.63 & 0.63 \\
\hline
\end{tabular}

Table IV: Complementary log-log estimation results

\begin{tabular}{|l|c|c|c|c|c|c|}
\hline \multicolumn{1}{|c|}{$\begin{array}{c}\text { Complementary log-log } \\
\text { estimation }\end{array}$} & Coefficient Estimate & \multicolumn{5}{|c|}{ Significance (p-value) } \\
\cline { 2 - 7 } & Gender & Coefficient Estimate & Model fit & Pearson & Deviance & $\begin{array}{c}\text { Test of Parallel } \\
\text { Lines }\end{array}$ \\
\hline On-time arrival/departure & 0.369 & 0.047 & 0.045 & 0.693 & 0.692 & 0.692 \\
\hline Frequency of service & 0.432 & 0.018 & 0.017 & 0.699 & 0.703 & 0.703 \\
\hline Seat availability & 0.481 & 0.008 & 0.007 & 0.79 & 0.792 & 0.792 \\
Departure times & 0.523 & 0.005 & 0.004 & 0.967 & 0.967 & 0.967 \\
Time to/from the airport & 0.692 & 0.024 & 0.019 & 0.545 & 0.547 & 0.547 \\
\hline Ease of access & 0.105 & 0.685 & 0.684 & 0.149 & 0.147 & 0.147 \\
Ease of check-in & 0.458 & 0.064 & 0.059 & 0.984 & 0.984 & 0.984 \\
Airport safety & 0.421 & 0.02 & 0.018 & 0.533 & 0.536 & 0.536 \\
\hline Parking security & 0.277 & 0.123 & 0.121 & 0.24 & 0.236 & 0.236 \\
\hline Price of ticket & 0.614 & 0 & 0 & 0.719 & 0.717 & 0.717 \\
\hline Cost of parking & 0.22 & 0.17 & 0.168 & 0.367 & 0.361 & 0.361 \\
\hline Cost of transport to the airport & 0.32 & 0.069 & 0.066 & 0.79 & 0.789 & 0.789 \\
\hline
\end{tabular}


Table V: Negative log-log estimation results

\begin{tabular}{|l|c|c|c|c|c|c|}
\hline \multirow{2}{*}{ Negative log-log estimation } & Coefficient Estimate & \multicolumn{5}{|c|}{ Significance (p-value) } \\
\cline { 2 - 7 } & Gender & Coefficient Estimate & Model fit & Pearson & Deviance & $\begin{array}{c}\text { Test of Parallel } \\
\text { Lines }\end{array}$ \\
\hline On-time arrival/departure & 0.34 & 0.033 & 0.034 & 0.874 & 0.873 & 0.873 \\
\hline Frequency of service & 0.231 & 0.134 & 0.137 & 0.123 & 0.122 & 0.122 \\
\hline Seat availability & 0.281 & 0.068 & 0.07 & 0.11 & 0.11 & 0.11 \\
\hline Departure times & 0.357 & 0.021 & 0.022 & 0.225 & 0.225 & 0.225 \\
\hline Time to/from the airport & 0.296 & 0.066 & 0.068 & 0.198 & 0.188 & 0.188 \\
Ease of access & 0.135 & 0.387 & 0.387 & 0.195 & 0.197 & 0.197 \\
Ease of check-in & 0.28 & 0.073 & 0.075 & 0.817 & 0.816 & 0.816 \\
Airport safety & 0.222 & 0.156 & 0.159 & 0.09 & 0.089 & 0.089 \\
Parking security & 0.114 & 0.485 & 0.487 & 0.094 & 0.09 & 0.09 \\
\hline Price of ticket & 0.552 & 0.001 & 0.001 & 0.228 & 0.223 & 0.223 \\
Cost of parking & 0.195 & 0.325 & 0.327 & 0.231 & 0.226 & 0.226 \\
\hline Cost of transport to the airport & 0.275 & 0.12 & 0.122 & 0.488 & 0.484 & 0.484 \\
\hline
\end{tabular}

The results indicate that the negative log-log (nlog-log) link does not result in significant regression models except in the case of the Price of the ticket. However, the complementary log-log (clog-log) link provides a better model fit if the Pearson and Deviance tests as well as the test of parallel lines are considered.

Although the test of parallel lines for the following attributes indicate that the null hypothesis cannot be rejected, no significant models could be estimated for the attributes based on overall model fit:

- Ease of access

- Ease of check-in

- Parking security

- Cost of parking

- Cost of transport to the airport [model fit significance $(\mathrm{n} \log -\log )=0.387$ ]

[model fit significance (logit) $=0.059$ ]

[model fit significance (clog-log) $=0.121$ ]

[model fit significance (clog-log) $=0.168$ ]

[model fit significance (clog-log) $=0.066$ ]

The lack of fit for these attributes indicates that female and male passengers rank these attributes similarly, i.e. there are no significant differences between the rankings of the response categories of these attributes by female and male passengers.

The ordinal regression results indicate that gender (female vs male) as the independent variable plays a significant role in the ranking of the response categories of the following attributes as summarised (in terms of model fit and link function) in Table VI. 
Table Vl: Summary of significant models

\begin{tabular}{|l|l|}
\hline \multicolumn{1}{|c|}{ Attribute } & Estimation model \\
\hline On-time arrival/departure & \multicolumn{1}{c|}{ Logit } \\
\hline Frequency of service & Complementary log-log \\
\hline Seat availability & Complementary log-log \\
\hline Departure times & Complementary log-log \\
\hline Time to/from the airport & Complementary log-log \\
\hline Airport safety & Complementary log-log \\
\hline Price of ticket & Complementary log-log \\
\hline
\end{tabular}

The positive parameter estimates for these attributes indicate that, based on the gender of the passengers, the higher response categories were more likely to be selected - which is why the complementary log-log link provides the best results. The respective response category probabilities are illustrated in Figures 1.1 to 1.7.

Fig 1.1 On-time arrival/departure

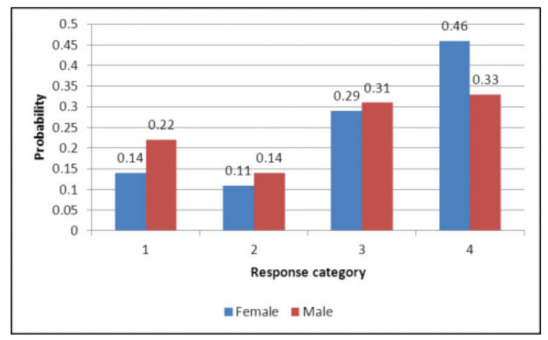

Fig 1.4 Departure times

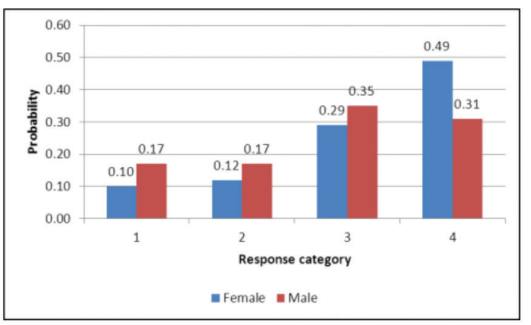

Fig 1.2 Frequency of service

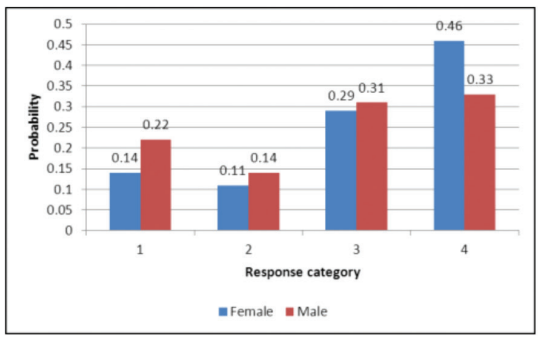

Fig 1.5 Time to/from the airport

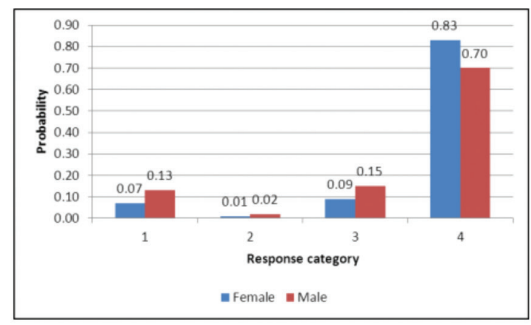

Fig 1.7 Price of the ticket

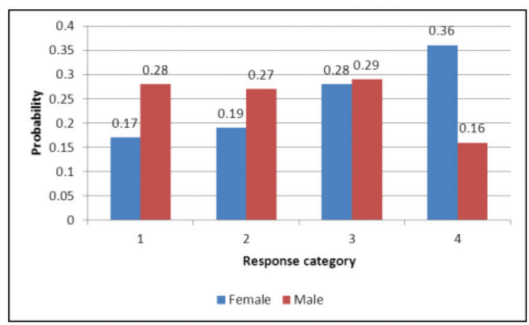

Fig 1.3 Seat availability

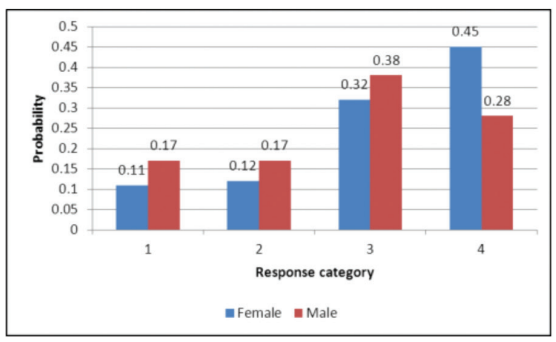

Fig 1.6 Airport safety

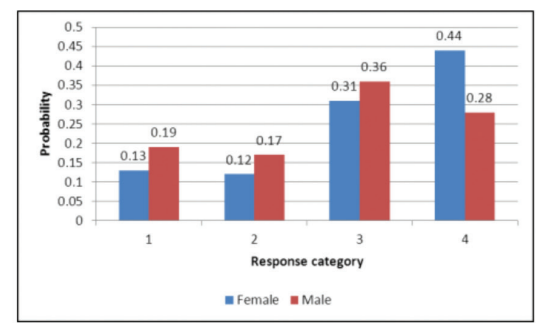

Figure 1: Response category probabilities by gender

It is evident from the estimated response probabilities that female and male passengers in general view the ranking of each attribute in a similar way, i.e. the higher rankings ( 3 and 4) have a higher probability of being selected. This is clearly illustrated in the case of Time 
to/from the airport where category 4 (to a large extent) has by far the highest probability of being selected. The one exception is the Price of the ticket where male passengers are more likely to select the lower three categories, indicating that the ticket price is less likely to influence a male passenger's decision at the highest level (to a large extent). The results also indicate that significant differences exist between the response category probabilities of female and male passengers. This is reflected by the fact that male passengers indicate that they are less likely to rate an attribute's influence on the airport decision to a large extent (category 4).

\section{Purpose of travel}

The results indicated that the purpose of travel (Business vs. Other) does not play a significant role in the selection of the response categories of the attributes except in the case of the price of the ticket. The results of the estimation models are shown in Tables VII to IX.

Table VII: Logit estimation results

\begin{tabular}{|l|c|c|c|c|c|c|}
\hline \multirow{2}{*}{\multicolumn{1}{|c|}{ Logit estimation }} & Coefficient Estimate & \multicolumn{5}{|c|}{ Significance (p-value) } \\
\cline { 2 - 7 } & Purpose of travel & Coefficient Estimate & Model fit & Pearson & Deviance & $\begin{array}{c}\text { Test of Parallel } \\
\text { Lines }\end{array}$ \\
\hline On-time arrival/departure & 0.155 & 0.544 & 0.544 & 0.962 & 0.962 & 0.962 \\
\hline Frequency of service & -0.174 & 0.491 & 0.493 & 0.04 & 0.04 & 0.04 \\
\hline Seat availability & -0.362 & 0.156 & 0.155 & 0.506 & 0.508 & 0.508 \\
\hline Departure times & -0.283 & 0.266 & 0.267 & 0.21 & 0.21 & 0.212 \\
\hline Time to/from the airport & 0.319 & 0.31 & 0.319 & 0.074 & 0.034 & 0 \\
Ease of access & 0.534 & 0.077 & 0.075 & 0.612 & 0.613 & 0.613 \\
Ease of check-in & -0.52 & 0.856 & 0.856 & 0.402 & 0.399 & 0.399 \\
Airport safety & 0.018 & 0.942 & 0.943 & 0.106 & 0.104 & 0.104 \\
\hline Parking security & 0.126 & 0.622 & 0.624 & 0.049 & 0.047 & 0.047 \\
\hline Price of ticket & -0.516 & 0.04 & 0.04 & 0.099 & 0.096 & 0.096 \\
Cost of parking & 0.427 & 0.11 & 0.109 & 0.315 & 0.314 & 0.314 \\
Cost of transport to the airport & 0.256 & 0.317 & 0.317 & 0.778 & 0.778 & 0.778 \\
\hline
\end{tabular}

Table VIII: Complementary log-log estimation results

\begin{tabular}{|l|c|c|c|c|c|c|}
\hline \multirow{2}{*}{$\begin{array}{c}\text { Complementary log-log } \\
\text { estimation }\end{array}$} & Coefficient Estimate & \multicolumn{5}{|c|}{ Significance (p-value) } \\
\cline { 2 - 7 } & Purpose of travel & Coefficient Estimate & Model fit & Pearson & Deviance & $\begin{array}{c}\text { Test of Parallel } \\
\text { Lines }\end{array}$ \\
\hline On-time arrival/departure & 0.105 & 0.56 & 0.56 & 0.948 & 0.948 & 0.948 \\
Frequency of service & -0.22 & 0.217 & 0.217 & 0.067 & 0.068 & 0.068 \\
\hline Seat availability & -0.283 & 0.108 & 0.107 & 0.676 & 0.678 & 0.678 \\
\hline Departure times & -0.259 & 0.149 & 0.148 & 0.324 & 0.327 & 0.327 \\
Time to/from the airport & 0.254 & 0.366 & 0.366 & 0.067 & 0.031 & 0 \\
\hline Ease of access & 0.471 & 0.067 & 0.065 & 0.688 & 0.688 & 0.688 \\
Ease of check-in & -0.062 & 0.794 & 0.794 & 0.409 & 0.406 & 0.406 \\
Airport safety & -0.082 & 0.64 & 0.64 & 0.118 & 0.116 & 0.116 \\
Parking security & -0.014 & 0.937 & 0.938 & 0.043 & 0.042 & 0.042 \\
Price of ticket & -0.42 & 0.01 & 0.01 & 0.321 & 0.319 & 0.319 \\
Cost of parking & 0.165 & 0.295 & 0.297 & 0.154 & 0.15 & 0.15 \\
Cost of transport to the airport & 0.145 & 0.399 & 0.4 & 0.673 & 0.672 & 0.672 \\
\hline
\end{tabular}


Table IX: Negative log-log estimation results

\begin{tabular}{|l|c|c|c|c|c|c|}
\hline \multirow{2}{*}{ Negative log-log estimation } & Coefficient Estimate & \multicolumn{5}{|c|}{ Significance (p-value) } \\
\cline { 2 - 7 } & Purpose of travel & Coefficient Estimate & Model fit & Pearson & Deviance & $\begin{array}{c}\text { Test of Parallel } \\
\text { Lines }\end{array}$ \\
\hline On-time arrival/departure & 0.098 & 0.537 & 0.536 & 0.969 & 0.969 & 0.969 \\
\hline Frequency of service & 0.049 & 0.749 & 0.75 & 0.034 & 0.033 & 0.033 \\
\hline Seat availability & -0.133 & 0.385 & 0.386 & 0.271 & 0.27 & 0.27 \\
\hline Departure times & -0.056 & 0.715 & 0.715 & 0.123 & 0.122 & 0.122 \\
\hline Time to/from the airport & 0.19 & 0.231 & 0.23 & 0.093 & 0.042 & 0 \\
\hline Ease of access & 0.216 & 0.164 & 0.163 & 0.333 & 0.333 & 0.333 \\
Ease of check-in & 0.026 & 0.866 & 0.866 & 0.403 & 0.398 & 0.398 \\
\hline Airport safety & 0.098 & 0.529 & 0.53 & 0.128 & 0.127 & 0.127 \\
\hline Parking security & 0.205 & 0.209 & 0.209 & 0.094 & 0.092 & 0.092 \\
\hline Price of ticket & -0.255 & 0.112 & 0.112 & 0.043 & 0.041 & 0.041 \\
\hline Cost of parking & 0.343 & 0.088 & 0.085 & 0.386 & 0.382 & 0.382 \\
\hline Cost of transport to the airport & 0.199 & 0.262 & 0.261 & 0.887 & 0.887 & 0.887 \\
\hline
\end{tabular}

The results indicate that only one significant model could be estimated (95\% significance). One of the reasons for the lack of fit is the fact that the proportional odds assumption (parallel lines) is not relevant (test of parallel lines significance $<0.05$ ) in some of the cases. In such cases it is proposed to use a less restrictive model such as the multinomial regression approach (Zhou et al., 2008). However, the multinomial regression approach did not result in significant models either.

No significant models could be estimated for the following attributes (overall model fit significance > 0.05):

- On-time arrival/departure

- Frequency of service

- Seat availability

- Departure times

- Time to/from the airport

- Ease of access

- Ease of check-in

- Airport safety

- Parking security

- Cost of parking

- Cost of transport to the airport [model fit significance $(n \log -\log )=0.537$ ]

[model fit significance (clog-log) $=0.217$ ]

[model fit significance (clog-log) $=0.107$ ]

[model fit significance (clog-log) $=0.148$ ]

[model fit significance $(\mathrm{n} l o g-\log )=0.230$ ]

[model fit significance (clog-log) $=0.065$ ]

[model fit significance (clog-log) $=0.794$ ]

[model fit significance $(n \log -\log )=0.530$ ]

[model fit significance $(n \log -\log )=0.209$ ]

[model fit significance $(n \log -\log )=0.085$ ]

[model fit significance $(n \log -\log )=0.261$ ]

The significance level for the fitted model for Ease of access is $93.5 \%$ ( $p$-value $=0.067$ ), which is relatively close to the generally accepted level of significance of $95 \%$. The positive coefficient (0.471) indicates that the higher rankings for this attribute are more likely to be selected. The calculated response probabilities are illustrated in Figure 2. 


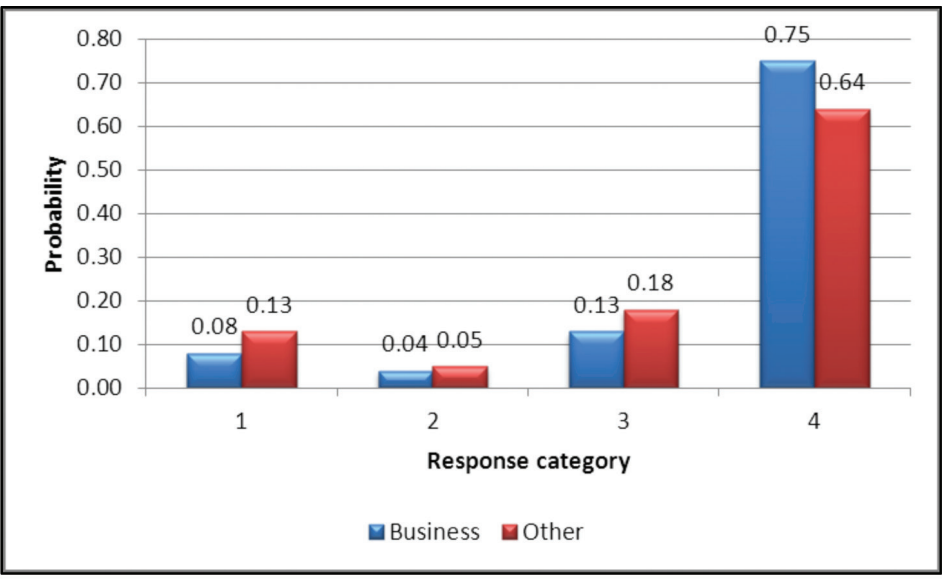

Figure 2: Response category probabilities - Ease of access (purpose of travel)

Figure 2 indicates that the highest response category ( $4=$ to a large extent) are the most likely to be selected by both Business and Other travellers. Although the general probability trend is the same for Business and Other travellers, it is clear that the influence of this attribute is ranked higher by business travellers, as indicated by the higher probability of selecting the highest ranking.

Similarly it could be argued that the significance for the fitted model for Cost of parking is relatively close to the generally accepted level of significance of 95\%, i.e. $91.5 \%$ (p-value $=0.085)$. The positive coefficient $(0.343)$ in this instance indicates that the lower rankings for this attribute are more likely to be selected. The calculated response probabilities are illustrated in Figure 3.

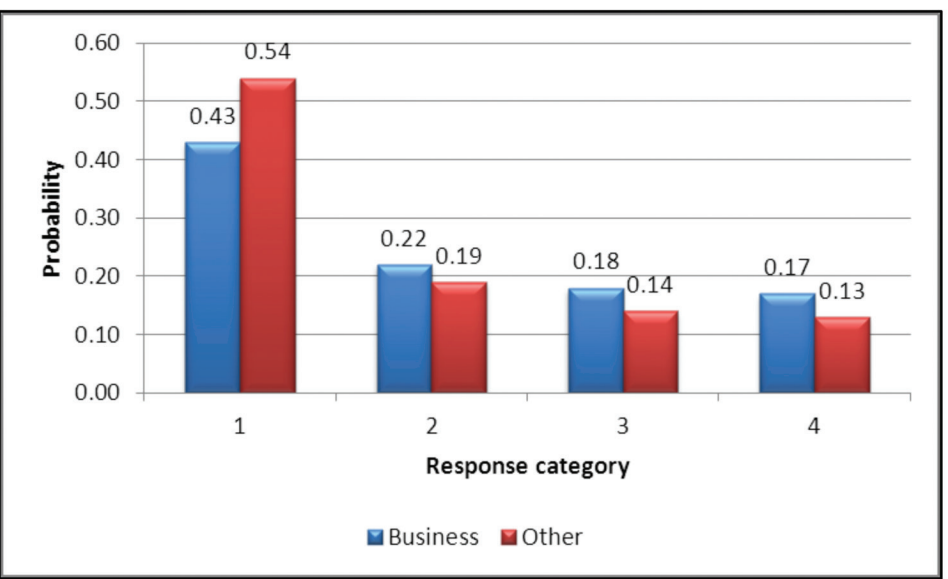

Figure 3: Response category probabilities - Cost of parking (purpose of travel)

The dominant probabilities for selecting the lowest response category ( $1=$ to no extent) indicates that business and other travellers are more likely to view the Cost of parking as having no influence on their airport decision. 
A significant model (model fit significance < 0.05) could only be fitted for the Price of the ticket (complementary log-log model). The negative coefficient estimate indicates that, based on the purpose of travel, business passengers are less likely to assess the influence of the Price of the ticket as influencing their airport decision to a large extent (response category 4). Figure 4 illustrates the estimated response probabilities by purpose of travel.

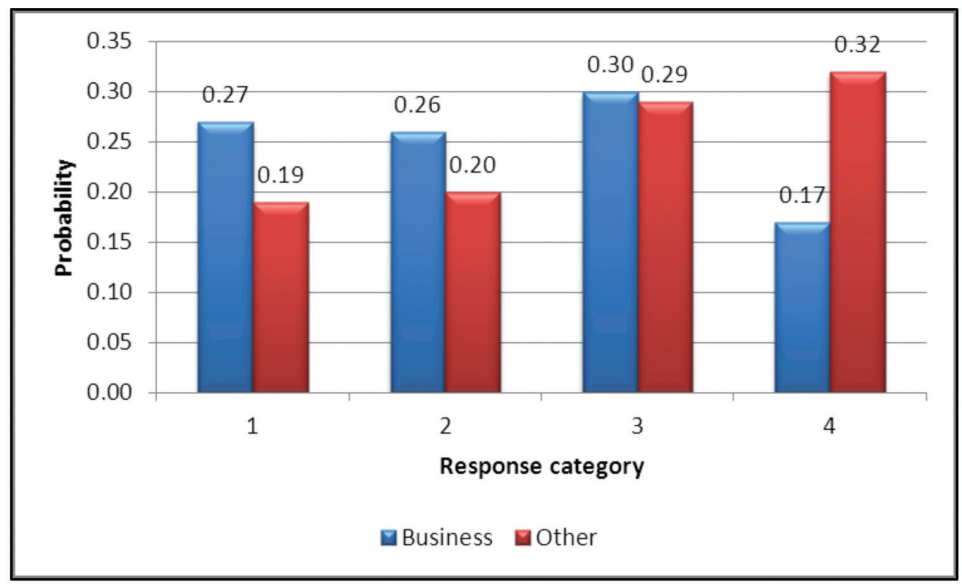

Figure 4: Response category probabilities - Price of the ticket (purpose of travel)

The estimated response category probabilities of business and other passengers differ significantly, especially with regard to the highest level ( $4=$ to a large extent). Other passengers are most likely to rank this attribute at the highest level, whereas Business passengers are least likely to rank this attribute at the highest level. This could be an indication that Other passengers are more likely to be cost-conscious at the highest level ( 4 = to a large extent). Based on the estimated response category probabilities for Business passengers it can be concluded that the Price of the ticket is mainly evaluated equally at all the levels of the attribute.

\section{CONCLUSION}

The impact of demographic variables (gender and purpose of travel) on the attributes that influence the choice of airport decision is important for the service providers (airport operator and airline) to understand the scope of the services to be provided to different segments of the market. This could be achieved by evaluating the extent (not important, very important, etc.) to which the demographic variables (gender and purpose of travel) influence the airport decision attributes.

This research focused on the results from passengers surveyed at LIA and the objective of the research is to utilise an ordinal regression model to gain an understanding of the influence of the gender of the passenger and the purpose of travel on the ranking of various attributes 
(level of importance) that influence their airport decision. Previous research identified 12 attributes as being important in the airport decision of passengers.

The ordinal regression approach was used since the respondents were requested to rank the influence of each attribute according to a Likert-type scale ( 1 = to no extent, $2=$ to a small extent, 3 = to a moderate extent and 4 = to a large extent). Although three types of link functions were used (logit, complementary log-log and negative log-log) the complementary log-log link in general provided the best overall model fit. This was mainly due to the fact that respondents generally selected the higher rankings.

The ordinal regression results indicate that gender (female, male) definitely influence the ranking of some of the attributes but not all. In general, female and male passengers used a similar ranking structure for the following five attributes (i.e. gender does not impact significantly on the ranking of the following attributes):

- Ease of access

- Ease of check-in

- Parking security

- Cost of parking

- Cost of transport to the airport

Significant differences exist in the response category probabilities of female and male passengers for the following seven attributes, i.e. gender impacts significantly on the ranking of the following attributes:

- On-time arrival/departure

- Frequency of service

- Seat availability

- Departure times

- Time to/from the airport

- Airport safety

- Price of ticket

Although female and male passengers rank these attributes differently, in general the respondents are more likely to select the higher rankings of the attributes ( $3=$ to a moderate extent and 4 = to a large extent). The one exception is the Price of the ticket which male respondents are less likely to rank at the highest level. Overall, male passengers are less likely to use the highest rank ( $4=$ to a large extent).

The purpose of travel (Business or Other) does not influence the ranking of the attributes significantly except in the case of the Price of the ticket. The estimated response probabilities indicate that the ranking of this attribute is similar for both Business and Other passengers 
and that the response categories 1 to 3 are equally likely to be selected. However, Business travellers are less likely to rank the Price of the ticket at the highest rank (4), whereas Other travellers are more likely to assess this attribute at the highest rank. Passengers that travel for 'other' purposes are clearly more conscious of the cost of travel.

The results indicate that the ordinal regression approach is a powerful tool to establish regression-type links between the various levels of ordinal dependent variables and demographic variables. The results of the ordinal regression approach (response category probabilities) can be used to estimate the likelihood of response category selection based on demographic variable levels. 


\section{REFERENCES}

Airports Company of South Africa (ACSA). 2011. Available from: http://www.acsa.co.za/ home. (Accessed 25 November 2011).

Akman, I. \& Mishra, A. 2010. Predictive effect of gender and sector differences on internet usage among employees. Engineering Economics, 21(3): 295-305.

Ananth, C.V. \& Kleinbaum, D.G. 1997. Regression models for ordinal responses: a review of methods and applications. International Journal of Epidemiology, 26 (6): 1323-33.

Bender, R. \& Benner, A. 2000. Calculating Ordinal Regression Models in SAS and S-Plus. Biometrical Journal, 42 (6): 677-99.

Chen, C.-K., \& Hughes, J. 2004. Using ordinal regression model to analyze student satisfaction questionnaire. IR Applications, 1: 1-13.

Comair Limited. 2011. Available from: http://www.comair.co.za/html/about_us.asp. (Accessed 25 November 2011).

Denham, B.E. 2010. Measurement of risk perceptions in social research: a comparative analysis of ordinary least squares, ordinal and multinomial logistics regression models. Journal of Risk Research, 13 (5): 571-89.

Eboli, L. \& Mazulla, G. 2009. An ordinal logistic regression model for analyzing airport passenger satisfaction. EuroMed Journal of Business, 4 (1): 40-57.

Hensher, D.A. Rose, J.M. \& Greene, W.H. 2006. Applied Choice Analysis A Primer. Cambridge: Cambridge University Press.

Hess, S., Adler, T. \& Polak, J.W. 2007. Modelling airport and airline choice behavior with the use of stated preference survey data. Transportation Research Part E: Logistics and Transportation Review, 43 (3): 221-33.

Heyns, G. \& Carstens, S. 2011. Passenger choice decisions at a regional airport in South Africa. Journal of Transport and Supply Chain Management, 5(1): 186-201.

Marcucci, E. \& Gatta, V. 2011. Regional airport choice: Consumer behavior and policy implications. Journal of Transport Geography, 19(1): 70-84. 
Norusis, M. 2011. IBM SPSS Statistics 19 Advanced Statistical Procedures Companion. Available from http://www.norusis.com. (Assessed 25 November 2011).

Pels, E., Nijkamp, P. \& Rietveld, P. 2003. Access to and competition between airports: a case study for the San Francisco Bay area. Transportation Research Part A: Policy and Practice, 37(1): 71-83.

Zhou, F., Wu, D., Yang, X. \& Jiao, J. 2008. Ordinal Logistic Regression for Affective Product Design. Conference proceeding of the IEEE conference held in Singapore. Conducted by Industrial Engineering and Engineering Management. Singapore: IEEE.

Table of acronyms and abbreviations

\begin{tabular}{|l|l|}
\hline ACSA & Airports Company of South Africa \\
\hline FCC & Full-Cost Carrier \\
\hline LIA & Lanseria International Airport \\
\hline LCC & Low-Cost Carrier \\
\hline ORTIA & OR Tambo International Airport \\
\hline VFR & Visiting Friends and Relatives \\
\hline
\end{tabular}

